Regular article

\title{
Improved acylation of phytosterols catalyzed by Candida antarctica lipase A with superior catalytic activity
}

\author{
Worawan Panpipat, Xuebing Xu, Zheng Guo* \\ Department of Engineering, Faculty of Science, Aarhus University, Gustav Wieds Vej 10, 8000 Aarhus C, Denmark
}

\section{A R T I C L E I N F O}

\section{Article history:}

Received 7 August 2012

Accepted 30 September 2012

Available online 9 October 2012

\section{Keywords:}

Phytosterol

$\beta$-Sitosterol

Fatty acids

Esterification

Candida antarctica lipase A (CAL A)

\begin{abstract}
A B S T R A C T
This work reported a novel approach to synthesize phytosterol ( $\beta$-sitosterol as a model) fatty acid esters by employing Candida antarctica lipase A (CAL A) which shows a superior catalytic activity to other lipases. A series of $\beta$-sitosteryl fatty acid esters (C2-C18) have been successfully prepared with structural identification of products by ${ }^{1} \mathrm{H}$ NMR and Fourier transform-infrared spectroscopy (FTIR). Compared to other immobilized lipases, CAL A achieves 6-14 times faster esterification of $\beta$-sitosterol with myristic acid. CAL A shows low activity toward short chain fatty acids (C2-C6), and remarkably high activity for medium and long chain ones $(\geq \mathrm{C} 8$ ). Reaction time, temperature, enzyme load, substrate ratio and concentration, and solvent property are found to profoundly influence reaction rates. A pronounced correlation between enzyme activities and $\log P$ values of solvents, among the solvents with a broad spectrum of $\log P$ values, was observed. 93-98\% yield of $\beta$-sitosteryl esters could be achieved with hexane as solvent, fatty acid (C8-C18)/ $\beta$-sitosterol (1:1, mol:mol), 5-10\% CAL A load at $40-50^{\circ} \mathrm{C}$ for $24 \mathrm{~h}$. This work demonstrated the promising potential of CAL A in bioprocess of phytosterols for value-added application.
\end{abstract}

(c) 2012 Elsevier B.V. All rights reserved.

\section{Introduction}

Phytosterols are numbers of triterpene family, particularly C29and C28-sterols consisting of a steroid skeleton with a hydroxyl group attached to the $\mathrm{C}-3$ atom of the A-ring and an aliphatic side chain attached to the $\mathrm{C}-17$ atom of the D-ring (see $\beta$ sitosterol as a representative structure in Fig. 1). Phytosterols have found a variety of applications in: (1) pharmaceuticals for production of therapeutic steroids [1]; (2) nutrition and functional foods by means of anti-cholesterol property [2], anti-cancer properties, anti-inflammatory, anti-artherogenicity activity, antioxidative activities [3-7] and anti-osteoarthritic properties [8] and (3) cosmetics as surfactants in creams and lipstick [9]. Recently, phytosterol products have been added into various commercial foods and drink products as a cholesterol-lowering agent [2,10] such as butter [11], low-fat yoghurt [12], low fat spreads, mayonnaise/salad dressing, cereal bars, chocolate, bakery products [13], milk [12,14], yoghurt minidrinks [15], orange juice [13] and beverage [16]. Abumweis et al. [13] suggested that the incorporation of phytosterols into spreads, mayonnaise/salad dressing, milk/yoghurt, was associated with a greater efficacy in LDL-cholesterol reduction than incorporation into other foods, suggesting the important role of the food matrix affecting the cholesterol-lowering property of phytosterols. The US Food and

\footnotetext{
* Corresponding author. Tel.: +45 8715 5528; fax: +45 86123178 .

E-mail address: guo@mb.au.dk (Z.Guo).
}

Drug Administration and the European Union Scientific Committee have thoroughly reviewed the safety of phytosterols before being used in functional foods [2].

Natural phytosterols have a low solubility in both water and fat, thus result in a poor intestine absorption [17]. For example, $50 \%$ of cholesterol entering the intestinal lumen can be absorbed whereas the absorptions of campesterol, $\beta$-sitosterol and $\beta$-sitostanol are in the ranges of $10-15 \%, 4-7 \%[18,19]$ and less than $1 \%$ [20], respectively. Hence, the effective dose of phytosterols is much high up to $25 \mathrm{~g} /$ day [21]. To improve the intestinal absorption and bioavailability of phytosterols, a feasible solution is to convert phytosterols into enzyme-liable lipophilic derivatives, such as fatty acid esters [22]. Miettinen and Vanhanen [22] have proved that that fat-soluble plant steryl and stanyl esters were able to lower plasma cholesterol level more efficiently than the corresponding homogenized crystalline plant sterol and stanol preparations.

Technical processes of chemical esterification or transesterification presently used for the preparation of steryl esters are generally performed at high temperature in the presence of chemical catalyst, accompanying with high energy consumption, browning of products and low selectivity [23]. As an alternative, enzymatic preparation of steryl esters has also been reported [24]. Lipases from Candida rugosa (lipase AYS), Rhizomucor miehei (Lipozyme TL IM), Pseudomonas sp. (lipase AK), Aspergilus niger (lipase AS), Candida antarctica B (CAL B) and Alcaligenes sp. (lipase QLM) have been used as biocatalysts [25-28]. In fact, the yields of phytosteryl esters catalyzed by those enzymes were generally low with longer reaction time. Vu et al. [27] examined lipase-catalyzed synthesis 

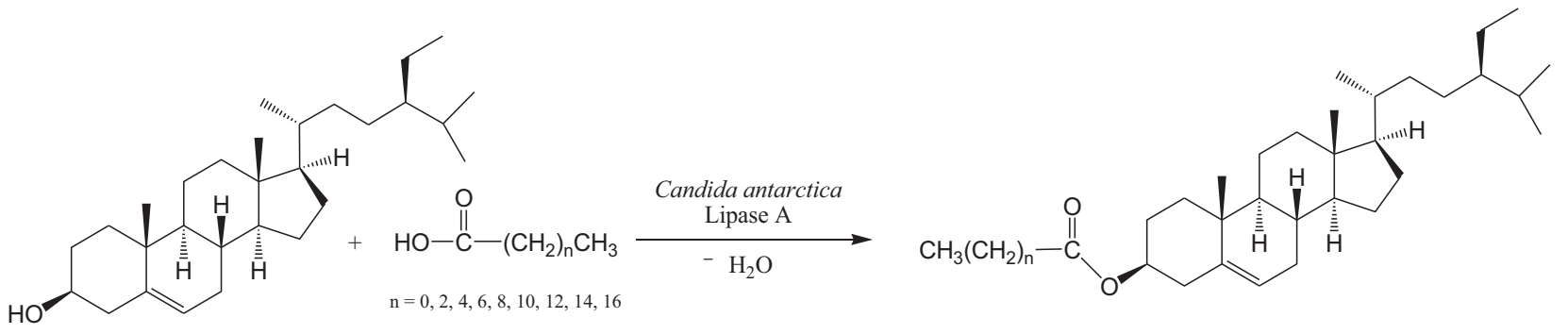

Fig. 1. Candida antarctica lipase A (CAL A) catalyzed esterification of $\beta$-sitosterol.

of $\beta$-sitosteryl esters of medium chain fatty acids (C6:0-C12:0), where AYS (from $C$. rugosa) was found to be the most effective to achieve $40.3 \%$ yield of $\beta$-sitosteryl laurate in $48 \mathrm{~h}$. Villeneuve et al. [25] obtained $85 \%$ yield of canola phytosterols of oleic acid in $72 \mathrm{~h}$ employing $C$. rugosa lipase as a biocatalyst. Albeit these progresses, developing more efficient reaction approach is still of academic and practical interests. C. antarctica lipase A (CAL A) is reported to have specific activity to accept highly branched acyl groups and sterically hindered alcohols as substrates [29]. This specificity of CAL A is of great interest for acylation of phytosterols which have a secondary alcohol and a bulky structure; however, to date employing CAL A as biocatalyst for acylation of phytosterols has not been investigated systemically. Thus, this work attempts to systemically examine the ability of CAL A in catalyzing acylation of phytosterols using $\beta$-sitosterol as a model substrate. The effects of enzyme concentration, substrate molar ratio, reaction temperature and time, and polar/non-polar organic solvents were intensively investigated. Primary results from this study indicate that the CAL $A$ is able to achieve 6-14 times efficiency for synthesis of $\beta$-sitosteryl fatty acid esters higher than most commercial immobilized lipases. The formation of $\beta$-sitosteryl esters with different fatty acids (C2-C18) was confirmed by ${ }^{1} \mathrm{H}$ NMR and Fourier transform-infrared spectroscopy (FTIR).

\section{Materials and methods}

\subsection{Lipases and chemicals}

$\beta$-Sitosterol, acetic acid (C2:0), butyric acid (C4:0), hexanoic acid (C6:0), octanoic acid (C8:0), decanoic acid (C10:0), lauric acid (C12:0), myristic acid (C14:0), palmitic acid (C16:0) and stearic acid (C18:0) were purchased from Sigma-Aldrich (St. Louis, MO, USA). Immobilized lipase $C$. antarctica lipase A, NZL-101 (CAL A) was purchased from Codexis, Inc., (Pasadena, CA, USA). Immobilized C. antarctica lipase B (CAL B, Lipozyme 435), immobilized Thermomyces lanuginosus (Lipozyme NS-40044 TLL) and immobilized $T$. lanuginosus (Lipozyme TL IM) were obtained from Novozymes A/S (Bagsvaerd, Denmark). All solvents such as acetone, acetonitrile, butanone, chloroform, ethyl acetate, $n$-propanol, $n$-hexane and $n$ heptane were of HPLC grade and obtained from Sigma-Aldrich (St. Louis, MO, USA). All the enzymes were used as received; no further treatment has been done.

\subsection{Lipase catalyzed synthesis of $\beta$-sitosterol-saturated fatty acid esters}

In a typical reaction, $\beta$-sitosterol was mixed with myristic acid (C14:0) at a mole ratio of $1.0: 1.0(\mathrm{~mol} / \mathrm{mol})$ at the concentration of $0.2 \mathrm{M}$ in $3 \mathrm{~mL}$ hexane in the presence of $10 \%$ lipase (wt\% of $\beta$ sitosterol). Myristic acid was selected as a model saturated fatty acid because of its preferable chain length $(>12$, belonging to long chain fatty acids $)$, lower melting point $\left(54.4^{\circ} \mathrm{C}\right)$ and better solubility (than palmitic and stearic acids) in many solvents. The reaction was conducted in a $10 \mathrm{~mL}$ capped vial at $50^{\circ} \mathrm{C}$ for $72 \mathrm{~h}$ with agitation at $500 \mathrm{rpm}$. The reaction was monitored with periodically sample withdrawing. The aliquot was dissolved in $1 \mathrm{~mL}$ hexane for HPLC analysis. To assess catalytic efficiency of the lipases from other sources, Lipozyme 435 (C. antarctica lipase B, CAL B), Lipozyme NS 40044 TLL (T. lanuginosus lipase) and Lipozyme TL IM (T. lanuginosus), which have been proven to the most effective enzymes in catalyzing transesterification of steryl esters [30], were employed as biocatalyst to carry out esterification of $\beta$-sitosterol with myristic acid.

\subsection{Parameterization of CAL A catalyzed synthesis of $\beta$-sitosteryl myristate}

Parameters considered important for enzymatic synthesis of $\beta$ sitosteryl ester in this work are reaction time, temperature, enzyme concentration, substrate ratio, substrate concentration and solvent property.

Effect of enzyme concentration on synthesis of $\beta$-sitosteryl myristerate was examined by varying CAL A concentrations from $3 \%$ to $30 \%$ (wt\% of $\beta$-sitosterol). The concentrations of both $\beta$-sitosterol and myristic acid were $0.2 \mathrm{M}$ with hexane as reaction solvent. The reaction was performed at $50^{\circ} \mathrm{C}$ with agitation at $500 \mathrm{rpm}$ for up to $72 \mathrm{~h}$. The reaction was monitored with periodically sample withdrawing and HPLC analysis.

Examination of the effect of mole ratio of myristic acid $/ \beta$ sitosterol was carried out similarly as for enzyme concentration, but the concentration of CAL A was fixed at $5 \%$, and mole ratio of myristic acid/ $\beta$-sitosterol varied from $5 / 1$ to $1 / 1$. The reaction was monitored with sample withdrawing at the set time and HPLC analysis.

Likewise, examination of the effect of reaction temperature was performed with varied temperature from $30,40,50$ to $60^{\circ} \mathrm{C}$, while other conditions were $0.2 \mathrm{M} \beta$-sitosterol and myristic acid in hexane, $5 \%$ enzyme load, and agitation at $500 \mathrm{rpm}$. The reaction progress was monitored with periodically sample withdrawing at the set time; and the aliquots were properly diluted in hexane for HPLC analysis.

Acetone, acetonitrile, butanone, $n$-hexane and $n$-heptane, chloroform, methyl tert-butyl ether (MTBE) and toluene with varied $\log P$ values were selected for evaluation of the effects of solvents. The reaction was conducted at $40{ }^{\circ} \mathrm{C}, 0.2 \mathrm{M} \beta$-sitosterol and myristic acid, $5 \%$ CAL A (wt\% of $\beta$-sitosterol), agitation at $500 \mathrm{rpm}$. The reaction progress was monitored by sampling at desired time.

Effect of substrate concentrations on synthesis of $\beta$-sitosteryl myristerate was studied by varying concentrations of $\beta$-sitosterol and myristic acid from 0.05 to $0.5 \mathrm{M}$ (the mole ratio of myristic acid $/ \beta$-sitosterol fixed at $1: 1)$ in the presence of $31.1 \mathrm{mg}$ CAL A ( $5 \%$, wt $\%$ of $\beta$-sitosterol at $0.5 \mathrm{M}$ ), with hexane as reaction solvent. The reaction was carried out at $50{ }^{\circ} \mathrm{C}$ with agitation at $500 \mathrm{rpm}$ for 
up to $24 \mathrm{~h}$. The reaction was monitored with periodically sample withdrawing and HPLC analysis.

\subsection{Preparation, purification and structural identification of $\beta$-sitosteryl saturated fatty acid esters}

A series of aliphatic fatty acid esters of $\beta$-sitosterol were prepared by a similar procedure as aforementioned with alternating fatty acids (C2:0-C18:0) as substrates to myristic acid. The reaction was typically performed at $40^{\circ} \mathrm{C}$ for up to $72 \mathrm{~h}$; the concentrations of $\beta$-sitosterol and fatty acid were $0.2 \mathrm{M}$, with hexane used as a solvent and 5\% CAL A (wt\% of $\beta$-sitosterol) employed. The reaction was monitored with periodically sample withdrawing and HPLC analysis. At the end of the reaction, the reaction was terminated by filtering out the enzyme.

The resulting reaction mixtures were applied to thin layer chromatography (TLC) on silica gel (silica gel 60 F254; E. Merck Co., Darmstadt, Germany) for purification of products. The plates were developed with cyclohexane/ethyl acetate $(4: 1, \mathrm{v}: \mathrm{v})$. Rf values of $\beta$ sitosterol, all saturated fatty acids and newly formed $\beta$-sitosteryl esters were $0.03,0.06$ and 0.83 , respectively. The band of $\beta$ sitosteryl esters was scraped, collected, and extracted by diethyl ether. The $\beta$-sitosteryl esters were then collected after diethyl ester was evaporated and subjected to structure identification by proton nuclear magnetic resonance $\left({ }^{1} \mathrm{H}\right.$ NMR) and Fourier transforminfrared (FTIR) spectroscopy.

The molecular structures of isolated $\beta$-stisterol fatty acid esters were identified by ${ }^{1} \mathrm{H}$ NMR analysis recorded on Varian Mercury $300 \mathrm{MHz}$ NMR spectrometer equipped with an Oxford Instruments Ltd. superconducting magnet (Palo Alto, CA, USA). $\mathrm{CDCl}_{3}$ was used as a solvent to dissolve samples and tetramethylsilane as the internal standard for ${ }^{1} \mathrm{H}$ NMR analysis. FTIR analysis of isolated $\beta$-sitosteryl ester was performed in a horizontal Attenuated Total Reflectance (ATR) Trough plate crystal cell ( $45^{\circ} \mathrm{ZnSe} ; 80 \mathrm{~mm}$ long, $10 \mathrm{~mm}$ wide and $4 \mathrm{~mm}$ thick) (PIKE Technology, Inc., Madison, WI) equipped with a Bruker Model Vector 33 FTIR spectrometer (Bruker Co., Ettlingen, Germany). Prior to the analysis, the crystal cell was cleaned with acetone, wiped dry with soft tissue and the background scan was run. For spectra analysis, sample $(10 \mathrm{mg} / \mathrm{mL}$ in methylene chloride) $(10 \mu \mathrm{L})$ was applied directly onto the crystal cell and the cell was clamped into the mount of the FTIR spectrometer. The spectra, in the range of $4000-400 \mathrm{~cm}^{-1}$ (mid-IR region) with automatic signal gain, were collected in 32 scans at a resolution of $4 \mathrm{~cm}^{-1}$ and were rationed against a background spectrum recorded from the cell with $10 \mu \mathrm{L}$ of methylene chloride at $25^{\circ} \mathrm{C}$. Analysis of spectral data was carried out using the OPUS 3.0 data collection software program (Bruker Co., Ettlingen, Germany).

\subsection{Reaction quantification by HPLC and statistical analysis}

The HPLC analysis of the reaction mixture for synthesis of $\beta$ sitosteryl ester was performed on Merck-Hitachi HPLC 7100 system (Merck, Darmstadt, Germany) equipped with a silica 60-column conjugated with an evaporative light scattering detector (ELSD, Alltech (Deerfield, IL)). The ELSD was operated at $40^{\circ} \mathrm{C}$ and nitrogen was used as a nebulizing gas at pressure of 2.2 bar and gain 6 . The flow rate was $1 \mathrm{~mL} / \mathrm{min}$. The column temperature was maintained at $40^{\circ} \mathrm{C}$. The elusion program of mobile phases follows a previous report by Torres et al. [31]. The area is used as weight for quantification calculation. The yield of $\beta$-sitosteryl fatty acid ester ( $\mathrm{mol} \%$ ) was expressed as the molar percentage of the product $\beta$-sitosteryl fatty acid ester of the sum of $\beta$-sitosteryl fatty acid ester plus unconverted $\beta$-sitosterol. The mole amount of product or unconverted $\beta$-sitosterol can be calculated by its area divided by its molecular weight.

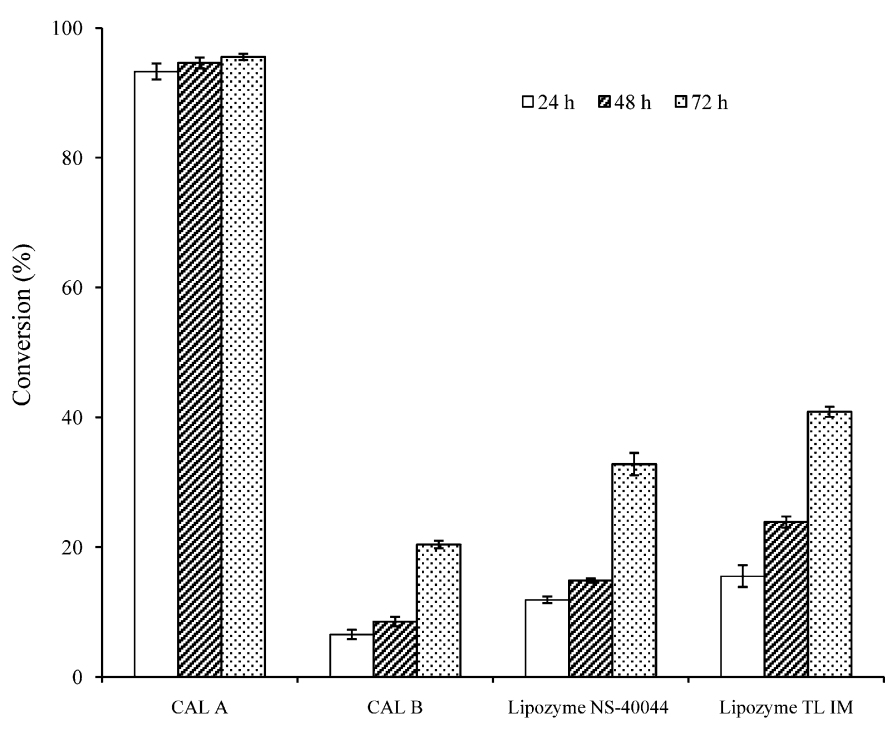

Fig. 2. Yields of $\beta$-sitosteryl myristate produced from $\beta$-sitosterol and myristic acid (C14:0) catalyzed by CAL A, CAL B, Lipozyme NS-40044 TLL or Lipozyme TL IM. Lipase-catalyzed esterification of $\beta$-sitosterol with myristic acid was performed in a $10 \mathrm{~mL}$ vial. The reaction conditions are: substrate concentration: $0.2 \mathrm{M} \beta$ sitosterol and $0.2 \mathrm{M}$ myristic acid; $3 \mathrm{~mL}$ hexane as solvent; lipase load $10 \%$ (wt\% of $\beta$-sitosterol); magnetic agitation at $500 \mathrm{rpm} ; 50{ }^{\circ} \mathrm{C}$ and $72 \mathrm{~h}$. Error bars represent the standard deviations of three separate determinations.

The data were subjected to analysis of variance (ANOVA). Comparison of means was carried out by Duncan's multiple range tests [32]. Statistical analysis was performed using the Statistical Package for Social Science (SPSS 11.0 for windows, SPSS Inc., Chicago, IL).

\section{Results and discussion}

\subsection{Superior efficiency of CAL A in catalyzing synthesis of steryl fatty acid esters}

In a recent work, we have observed the striking efficiency of three immobilized lipases, namely Lipozyme 435 (CAL B), Lipozyme NS-40044 TLL and Lipozyme TL IM in catalyzing alcoholysis of deodorizer distillates (DODs) for recovery of phytosterols [30]. While in some studies CAL A is reported to have extraordinary activity for secondary alcohols [29]. Hence, this work starts with examining the effectiveness of these four lipases in catalyzing synthesis of phytosteryl fatty acid esters using $\beta$-sitosterol and myristic acid as model substrates (Fig. 2). As shown in Fig. 2, it is clear that CAL A shows remarkably higher efficiency than the other three lipases, which achieves $93.3 \%$ yield of $\beta$-sitosteryl myristate in the first $24 \mathrm{~h}$; while Lipozyme 435, Lipozyme NS-40044 TLL and Lipozyme TL IM only achieve a corresponding yield of $6.5 \%, 11.8 \%$ and $15.5 \%$, respectively. Based on the above data, it is concludable that CAL A exhibits over 6-14 times faster than the other three immobilized lipases (The actually initial reaction rate of CAL A may be even over 6-14 times higher than the other three lipases because the other three enzymes achieve $<20 \%$ in $24 \mathrm{~h}$ which is in a liner range of conversion vs time; while CAL A already achieves $>90 \%$ which is out of the linear range). Even though with reaction time prolonged to $72 \mathrm{~h}$, Lipozyme TL IM only achieves a yield of $40.8 \%$, Lipozyme NS-40044 TLL 32.8\% and Lipozyme 435 20.4\%, respectively; while CAL A further enhanced to $95.5 \%$. The observed results of the other three immobilized lipases in this work agree with previous reports $[23,27,29]$. For instance, lipase AYS (from $C$. rugosa) catalyzed synthesis of $\beta$-sitosteryl laureate in hexane the yield for $48 \mathrm{~h}$ was reported to be $40.3 \%$ [27]; and the observed yield of 


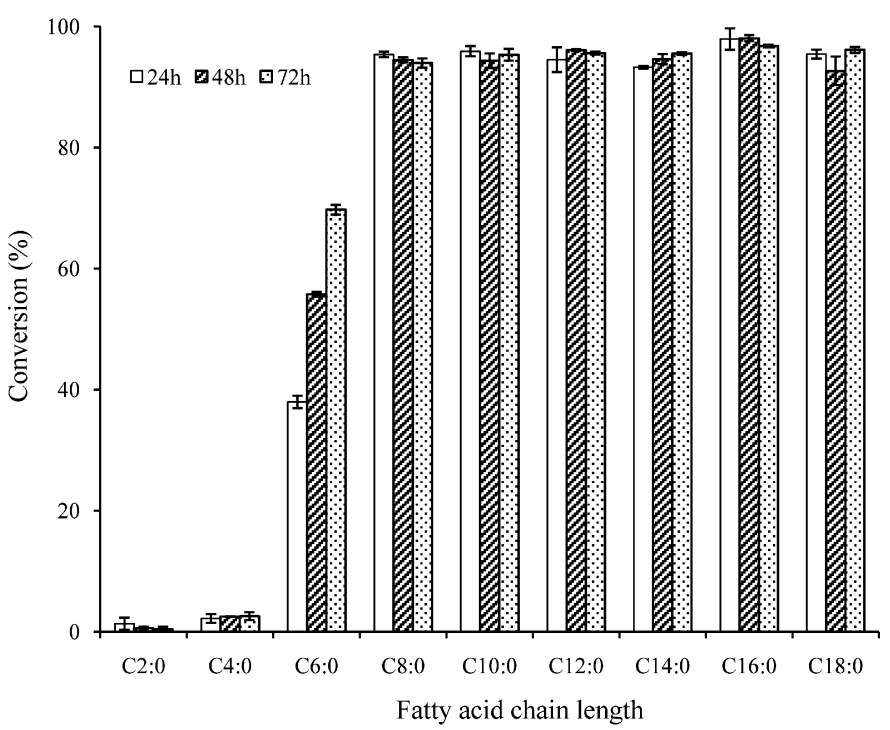

Fig. 3. Effect of fatty acid chain length on the yield of $\beta$-sitosteryl ester produced by CAL A-catalyzed esterification of $\beta$-sitosterol with saturated fatty acids. CAL Acatalyzed esterification of $\beta$-sitosterol with different fatty acid was performed in a $10 \mathrm{~mL}$ vial. The reaction conditions are: substrate concentration: $0.2 \mathrm{M} \beta$-sitosterol and $0.2 \mathrm{M}$ fatty acid; $3 \mathrm{~mL}$ hexane as solvent; lipase load $5 \%$ (wt\% of $\beta$-sitosterol); magnetic agitation at $500 \mathrm{rpm} ; 40^{\circ} \mathrm{C}$ and $72 \mathrm{~h}$. Error bars represent the standard deviations of three separate determinations.

$\beta$-sitosteryl laureate catalyzed by Novozym 435 (CAL B) was $79.3 \%$ while the reaction time added up to $96 \mathrm{~h}$ [23]. Clearly, CAL A shows a remarkably superior catalytic property to other known lipases $[23,27,29]$. Thus, CAL A was selected as a central biocatalyst in this work to examine its catalytic behavior in enzymatic synthesis of phytosteryl fatty acid esters.

\subsection{Synthesis and structural identification of a series of $\beta$-sitosteryl saturated fatty acid esters}

With CAL A as a catalyst, a series of $\beta$-sitosteryl aliphatic esters (C2-C18) have been synthesized (Fig. 1) and the results were presented in Fig. 3. As indicated in Fig. 3, it is clear that from acetic to octanoic acid the yields of $\beta$-sitosteryl esters depend largely on chain lengths of fatty acids. Lower than $5 \%$ yield of $\beta$-sitosteryl esters of acetic and butyric acids; approximate $38 \%$ yield is obtained for hexanoic acid. When fatty acid chain length $\geq 8$, higher than $90 \%$ yields of $\beta$-sitosteryl esters are obtained but no significant difference can be observed among them (Fig. 3). Certainly, with the increase of chain length of aliphatic carboxylic acids, some properties of them, such as acidicity (pKa), hydrophobicity $(\log P)$ and aqueous solubility, may change accordingly [33,34]. Acetic and butyric acids are strong organic acids. Most likely the lower activity of CAL A with acetic and butyric acid is because their strong acidity, which may greatly deactivate the enzyme [34-36]. While hexanoic acid is weaker than as acetic and butyric acids; therefore, the yield of $\beta$-sitosteryl ester of hexanoic acid is remarkably higher. After octanoic acid, the acid induced deactivation can no longer be a decisive factor [35].

Furthermore, the generally excellent activity of CAL A in catalyzing synthesis of $\beta$-sitosteryl esters of medium and long chain fatty acids again demonstrated its unique property to accept bulky alcohols ( $\beta$-sitosterol) and fatty acids [29]. It should also be noted that the catalytic efficiency of CAL A is strikingly higher than previous reports which among the reactions generally lower yields were obtained in even longer reaction time $[23,27]$.

Two methods (FTIR and ${ }^{1} \mathrm{H}$ NMR) have been used to identify the molecule structures of synthesized $\beta$-sitosteryl saturated fatty acid

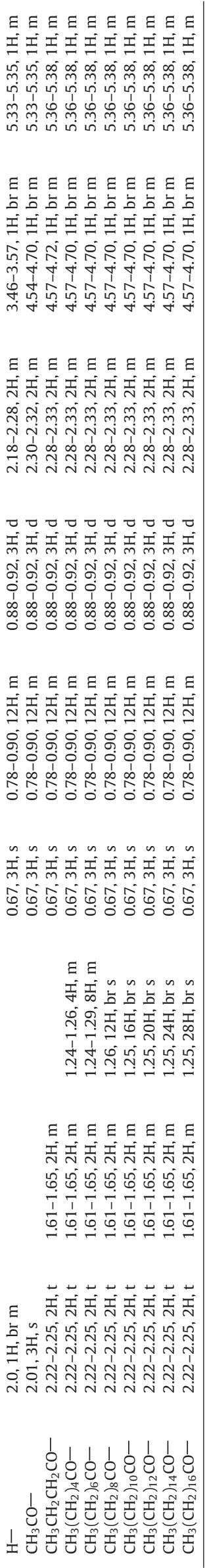



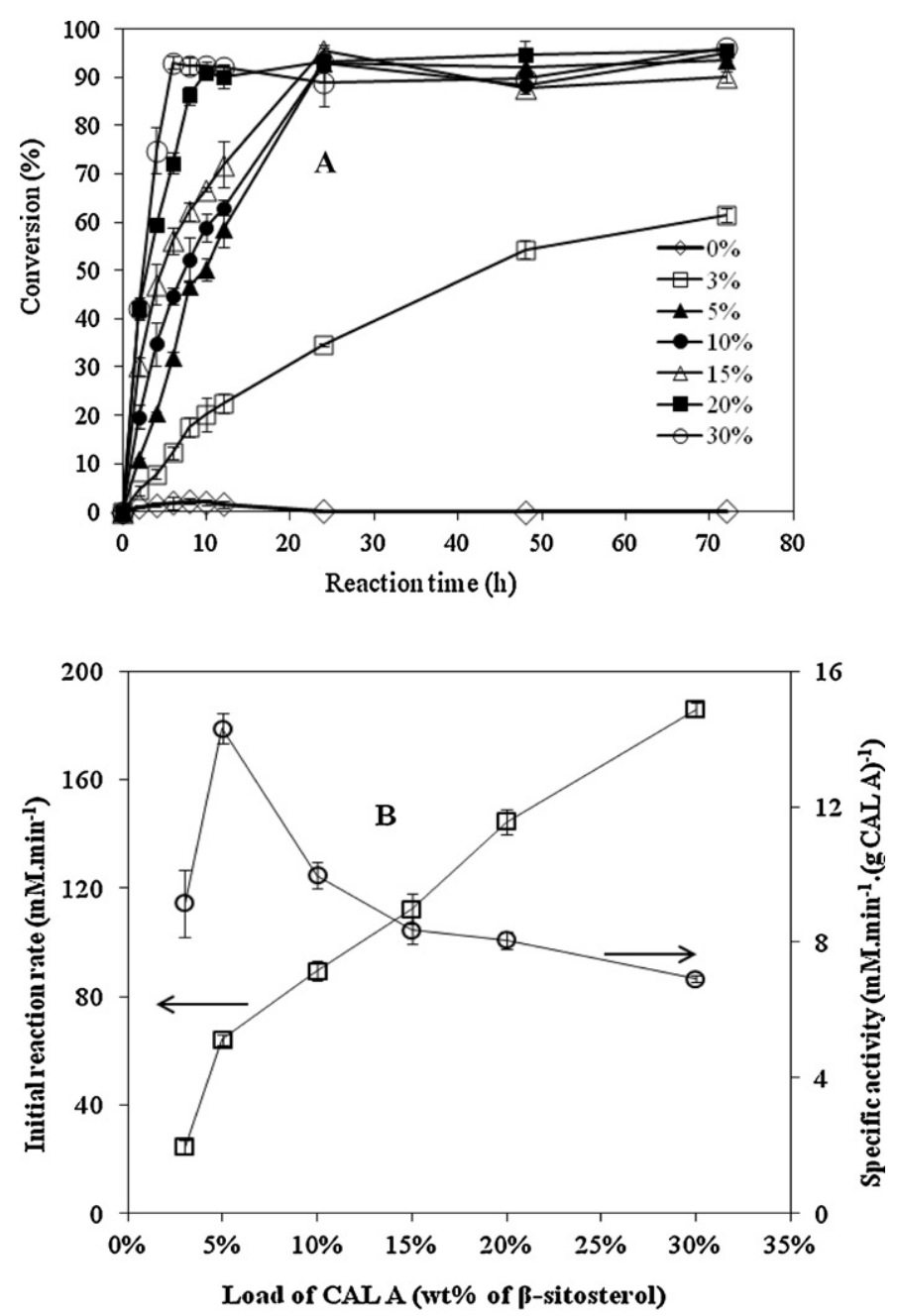

Fig. 4. (A) Effect of CAL A concentration on the yield of $\beta$-sitosteryl myristate; (B) initial reaction rates and specific activities at different concentrations of CAL A. CAL A-catalyzed esterification of $\beta$-sitosterol with myristic acid was performed in a $10 \mathrm{~mL}$ vial. The reaction conditions are: substrate concentration: $0.2 \mathrm{M} \beta$-sitosterol and $0.2 \mathrm{M}$ myristic acid; $3 \mathrm{~mL}$ hexane as solvent; CAL A load $0-30 \%$ (wt\% of $\beta$ sitosterol); magnetic agitation at $500 \mathrm{rpm} ; 50^{\circ} \mathrm{C}$ and $72 \mathrm{~h}$. The initial reaction rates and specific activities were calculated based on a linear function of the conversion of $\beta$-sitosterol vs reaction time at the first $6 \mathrm{~h}$. Error bars represent the standard deviations of three separate determinations.

esters. Before analysis the pure product was prepared by separation with preparative TLC. The IR absorption spectrum of $\beta$-sitosterol shows an absorption at $1710.7 \mathrm{~cm}^{-1}$ which is from $\mathrm{C}-\mathrm{O}$ stretch $(-\mathrm{C}-\mathrm{O}-\mathrm{H})$ and absorption bands at $3342.0-3401.7 \mathrm{~cm}^{-1}$ indicating existence of $-\mathrm{O}-\mathrm{H}(\mathrm{O}-\mathrm{H}$ stretch $)$. For all $\beta$-sitosteryl fatty acid esters there are one absorption at 1710.7 ( $\mathrm{C}-\mathrm{O}$ stretch in moiety of $\beta$-sitosteryl group) and a strong absorption at $1741.6 \mathrm{~cm}^{-1}(\mathrm{C}=\mathrm{O}$ stretch in moiety of acyl group), indicating an acyl group introduced [37].

The molecular structures of synthesized products were also identified by individual ${ }^{1} \mathrm{H}$ NMR analysis and characteristic chemical shifts have been detailed in Table 1 . In ${ }^{1} \mathrm{H}$ NMR spectrum of all $\beta$-sitosteryl esters, the signal at $\delta 2.0(1 \mathrm{H}$, br m) disappears indicating- $\mathrm{OH}$ was esterified; while the signals at $\delta 2.22-2.25$ $(2 \mathrm{H}, \mathrm{t})$ and $\delta 1.61-1.65(2 \mathrm{H}, \mathrm{m})$ indicate the introduction of $-\mathrm{CH}_{2} \mathrm{CH}_{2} \mathrm{CO}-$ (Table 1 ). The length of carbon chain can be recognized by the $H$ number of the signal at $\delta 1.24-1.29$ [38]. In all, FTIR and ${ }^{1} \mathrm{H}$ NMR data confirmed the successful syntheses of a series of $\beta$-sitosteryl fatty acid esters catalyzed by CAL A.

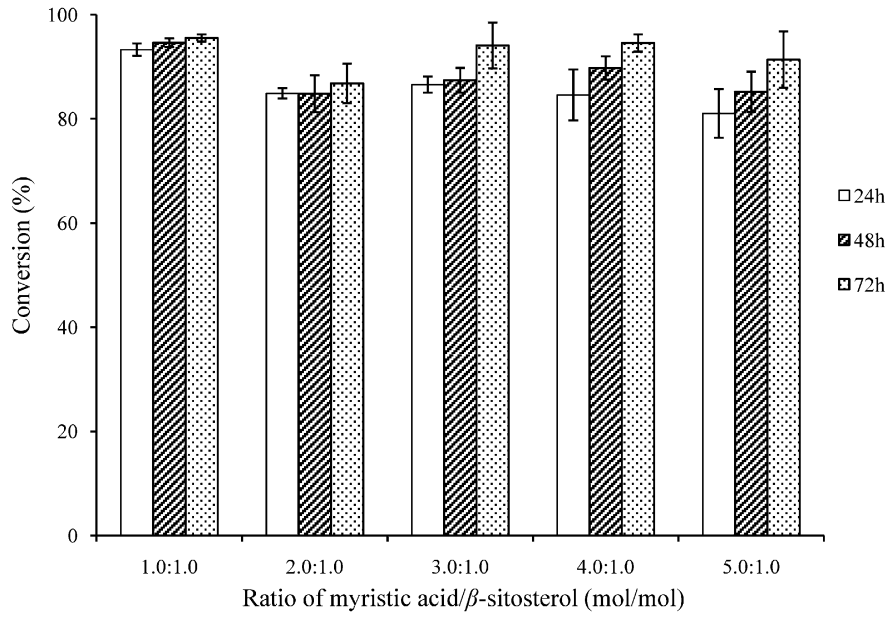

Fig. 5. Effect of mole ratio of myristic acid/ $\beta$-sitosterol on the yield of $\beta$-sitosteryl myristate. CAL A-catalyzed esterification of $\beta$-sitosterol with myristic acid was performed in a $10 \mathrm{~mL}$ vial. The reaction conditions are: substrate concentration: $0.2 \mathrm{M}$ $\beta$-sitosterol, and myristic acid varied at $0.2,0.4,0.6,0.8$ and $1.0 \mathrm{M} ; 3 \mathrm{~mL}$ hexane as solvent; CALA load $5 \%$ (wt\% of $\beta$-sitosterol); magnetic agitation at $500 \mathrm{rpm} ; 50{ }^{\circ} \mathrm{C}$ and $72 \mathrm{~h}$. Error bars represent the standard deviations of three separate determinations.

\subsection{Effects of the concentrations of CAL A on synthesis of $\beta$-sitosteryl myristate}

The effect of the load of CALA on synthesis of $\beta$-sitosteryl myristate is presented in Fig. 4A. The increase in enzyme concentrations from $3-30 \%$ shows a pronounced correlation with the yield of $\beta$ sitosteryl esters $(P<0.05)$. The time required to reach a maximal yield was greatly reduced with increasing enzyme concentration $(P<0.05)$. Enzyme load of $30 \%$ resulted in a maximal yield within $6 \mathrm{~h}$ whereas the enzyme load of $20 \%, 15 \%, 10 \%$ and $5 \%$ resulted in their maximal yields (>90\%) at 10,24, 24 and $24 \mathrm{~h}$, respectively. During the time course of prolongation to $72 \mathrm{~h}$, the yield of $\beta$-sitosteryl myristate catalyzed by 5-30\% CAL A varied in a narrow range of 93-97\% (Fig. 4A), indicating the equilibrium has been arrived at before $24 \mathrm{~h}$. Obviously for 3\% CAL A the equilibrium has not been reached until $72 \mathrm{~h}$. In the absence of biocatalyst, very low concentration of product was detected in the first $12 \mathrm{~h}$ but disappeared with the reaction progress, which probably the automatic esterification was reversed (Fig. 4A).

To evaluate the efficiency of CAL A, the initial reaction rates and specific activities are plotted as a function of enzyme loads (Fig. 4B). As shown in Fig. 4B, the overall reaction rate increases with increasing concentration of CAL A; however, the specific activity declines as enzyme load increases after $5 \%$ of CALA load. A maximum specific activity was obtained at an enzyme load of 5\% (Fig. 4B). Excellent time-space efficiency is an important index to assess a process for industrial interests [40]. Considering acceptable yield ( $>93 \%$ in $24 \mathrm{~h}$ ) and better specific activity, 5-10\% CAL A load will be a preferable range for the concentration of CAL A. Therefore, 5\% CAL A was selected as an optimum concentration for the rest of the study.

\subsection{Effects of mole ratios of substrates on synthesis of $\beta$-sitosteryl myristate}

The effect of mole ratio of myristic acid $/ \beta$-sitosterol on the yield of $\beta$-sitosteryl myristate is shown in Fig. 5 . At $24 \mathrm{~h}$, the yield of $\beta$-sitosteryl myristate at the stoichiometric ratio is $93.3 \%$; however the yield decreases significantly to $81.0-86.6 \%$ when higher mole ratio of myristic acid (myristic acid/ $\beta$-sitosterol, 2:1-5:1) is employed $(P<0.05)$ (Fig. 5). However, at $72 \mathrm{~h}$ the difference of the yields at differing substrate ratios is not as remarkable as at $24 \mathrm{~h}$ (Fig. 5). For example, except for at mole ratio of 

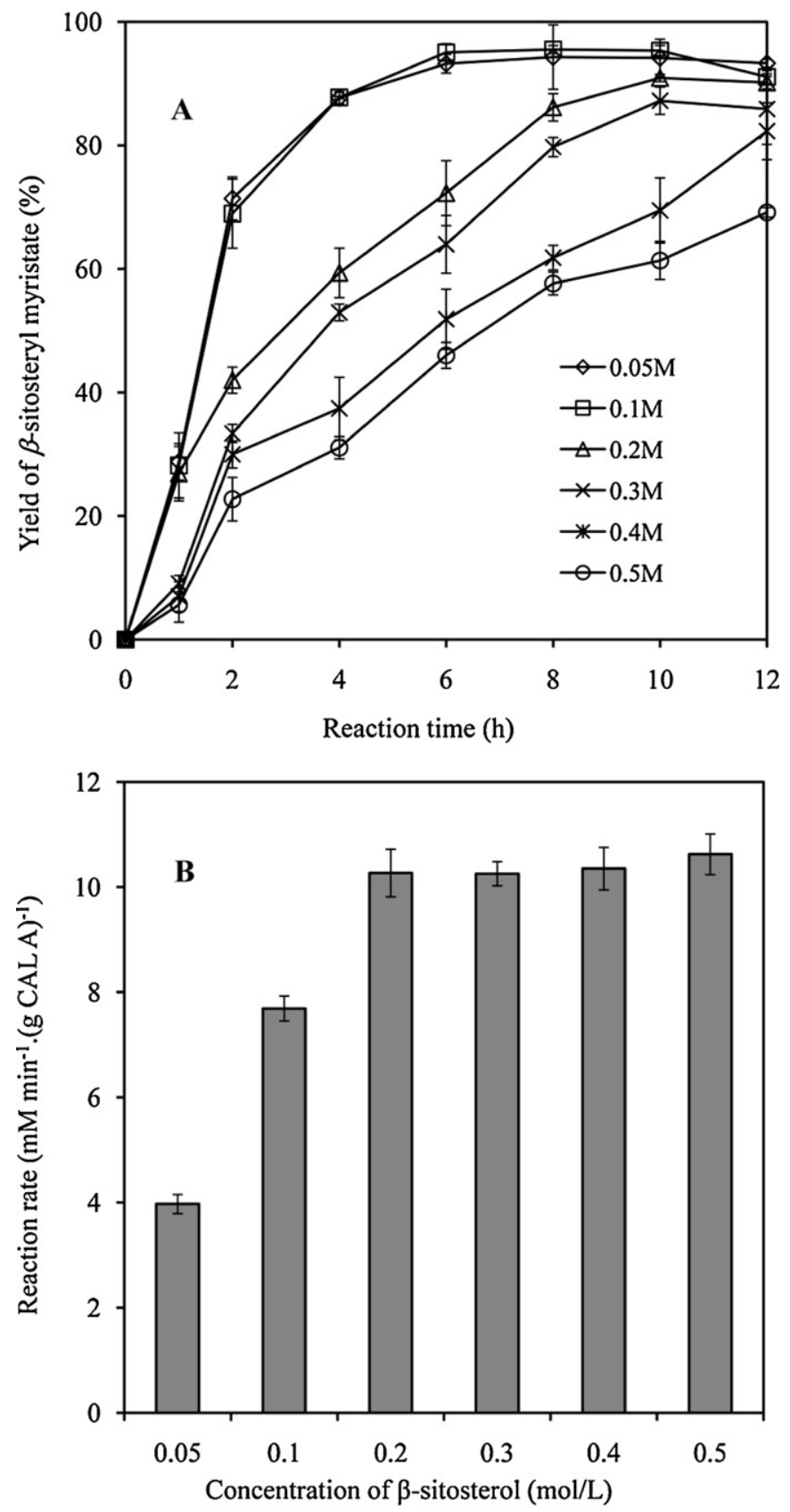

Fig. 6. Effects of substrate concentrations on the yield of $\beta$-sitosteryl myristate (A) and reaction rate $(B)$. The reaction rate was estimated as the initial velocity at the first $2 \mathrm{~h}$. CAL A-catalyzed esterification of $\beta$-sitosterol with myristic acid was performed in a $10 \mathrm{~mL}$ vial. The reaction conditions are: substrate concentrations, both $\beta$-sitosterol and myristic acid varied from 0.05 to $0.50 \mathrm{M} ; 3 \mathrm{~mL}$ hexane as solvent; CAL A load $31.1 \mathrm{mg}$ ( $5 \%$, wt \% of $\beta$-sitosterol at $0.5 \mathrm{M}$ ); magnetic agitation at $500 \mathrm{rpm}$; $50{ }^{\circ} \mathrm{C}$ and $24 \mathrm{~h}$. Error bars represent the standard deviations of three separate determinations.

(myristic acid/ $\beta$-sitosterol 2:1), the yield of $\beta$-sitosteryl myristate varies from $91.4 \%$ to $94.6 \%$ with substrate mole ratio varying from $3: 1$ to $5: 1$, close to the yield at $1: 1$. This result seems to be contradictory to the principle of reaction equilibration. From reaction equilibrium point of view, for a 2 reactants reaction, at a specific temperature (the equilibrium is a constant) an increase in the concentration of one reactant will lead to the decrease of the concentration of the other reactant; which means the increase of the ratio of myristic acid (corresponding to the increase of the concentration of myristic acid) should lead to the decrease of the concentration of $\beta$-sitosterol when the equilibration is reached

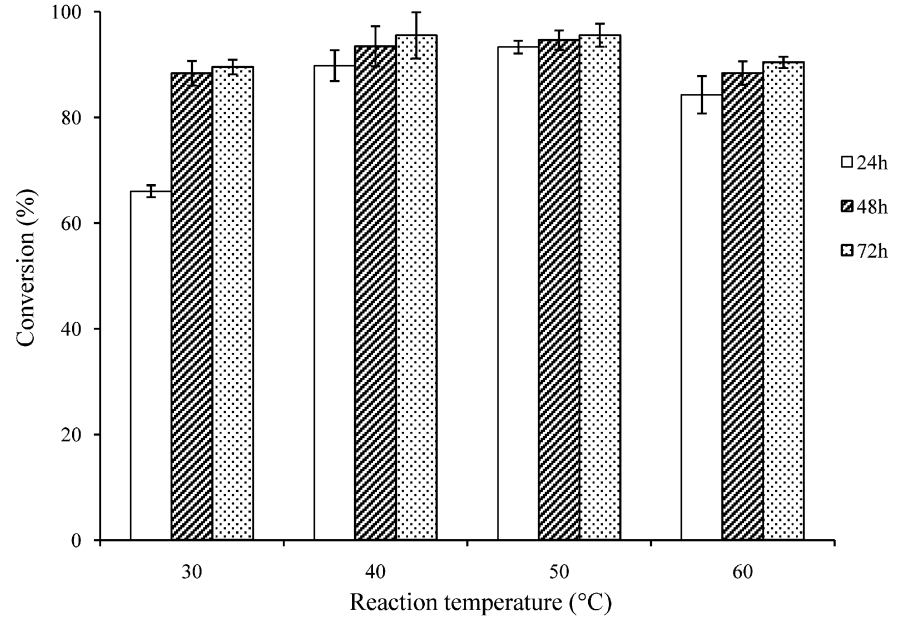

Fig. 7. Effect of reaction temperature on the yield of $\beta$-sitosteryl myristate. CAL Acatalyzed esterification of $\beta$-sitosterol with myristic acid was performed in a $10 \mathrm{~mL}$ vial. The reaction conditions are: substrate concentration: $0.2 \mathrm{M} \beta$-sitosterol, and $0.2 \mathrm{M}$ myristic acid; $3 \mathrm{~mL}$ hexane as solvent; CAL A load $5 \%$ (wt\% of $\beta$-sitosterol); magnetic agitation at $500 \mathrm{rpm}$; temperature varied from 30 to $60^{\circ} \mathrm{C}$ and $72 \mathrm{~h}$. Error bars represent the standard deviations of three separate determinations.

[23]. To explain the phenomenon of increasing myristic acid leading to decreasing conversion of $\beta$-sitosterol, we made a literature study about solubility of $\beta$-sitosterol and myristic acid and found out their solubilities in hexane at $50{ }^{\circ} \mathrm{C}$ are $0.003774(1.79 \mathrm{~g} / 100 \mathrm{~g})$ and 0.4384 by molar fraction, respectively [39]. However, the applied concentration of $\beta$-sitosterol is $0.2 \mathrm{M}(11.24 \mathrm{~g} / 100 \mathrm{~g})$ in this work, which means not all $\beta$-sitosterol is dissolved. We thus suspect that there are maybe two reasons accounting for the decreasing conversion of $\beta$-sitosterol at increasing concentration of myristic acid: (1) increasing myristic acid leads to a decrease of solubility of $\beta$-sitosterol in hexane (increasing cloudiness has been experimentally observed at higher concentration of myristic acid), which may delay the time to reach the equilibration. (2) undissolved $\beta$ sitosterol influences mass transfer and activity of CAL A. This could well explain why at longer reaction time the yield of the reaction at higher myristic acid can be improved significantly. In short, the result in Fig. 5 suggests that the stoichiometric ratio of myristic acid $/ \beta$-sitosterol is preferable to achieve maximum conversion of $\beta$-sitosterol.

\subsection{Effects of substrate concentrations on synthesis of $\beta$-sitosteryl myristate}

The effects of substrate concentrations on the yield of $\beta$ sitosteryl myristate (A) and initial rate (B) are depicted in Fig. 6. A general observation from Fig. 6A is that the yield of $\beta$-sitosteryl myristate decreases as the concentration of substrates increases. No significant difference in terms of the yield of $\beta$-sitosteryl myristate is observed at 0.05 and $0.1 \mathrm{M}$; however, the decrease in the yield of $\beta$-sitosteryl myristate against the increase of substrate concentration is being more significant when the concentration is $>0.2 \mathrm{M}$. This is very logical because for a certain concentration of enzyme, the actual reaction rate is somewhat dependent on enzyme concentration and the degree of the enzyme active sites saturated by the substrates. This can be more illustratively explained by the changes of initial rates when different substrate concentrations applied (Fig. 6B). As can be seen, no further significant increase of initial reaction rate as the increase of substrate concentration is observed when substrate concentration is $>0.2 \mathrm{M}$. This indicates that for the applied CAL $A$ in the reaction mixture their active sites are saturated by the substrates at $\geq 0.2 \mathrm{M}$. This result also indicates that at $0.2 \mathrm{M}$ 


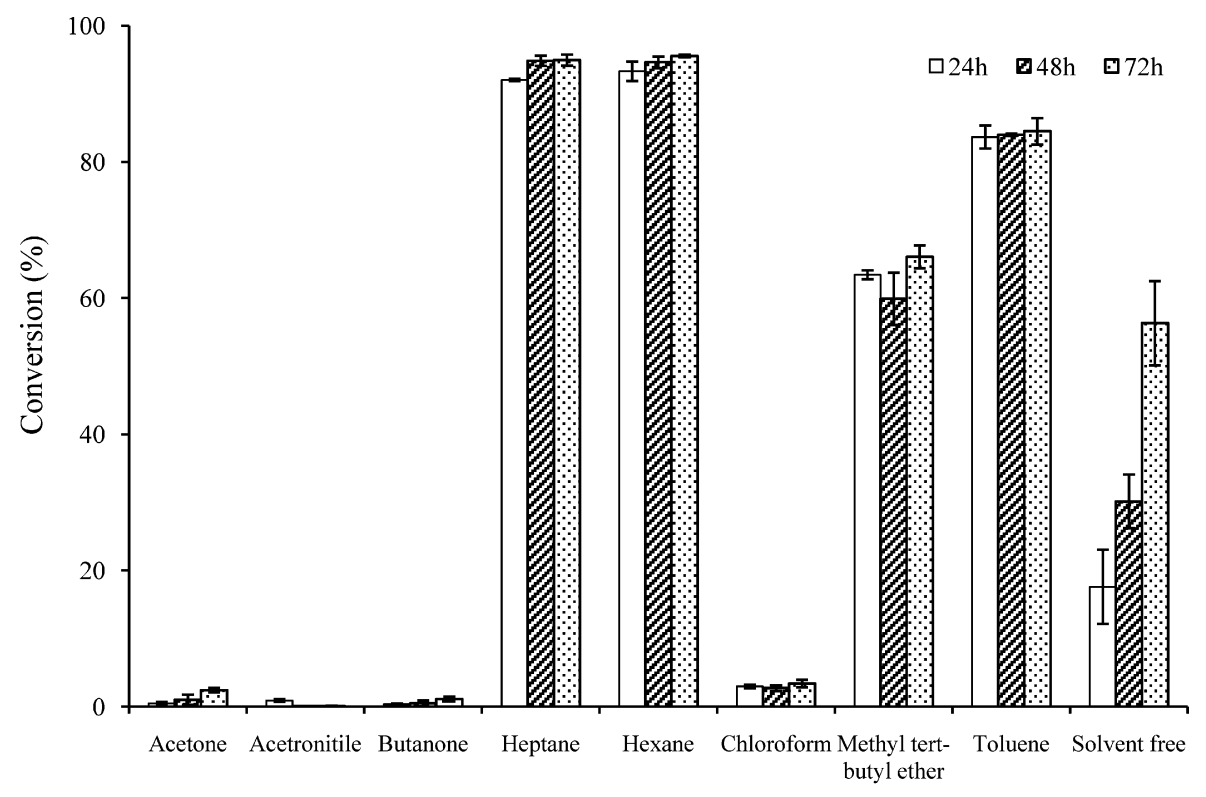

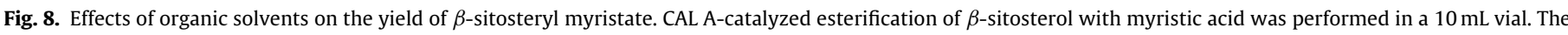

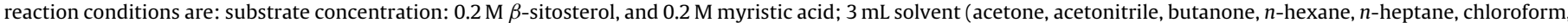

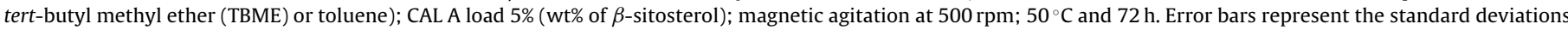
of three separate determinations.

$\beta$-sitosterol/myristic acid the $5 \%$ enzyme load is a proper dosage, or vice versa. However, with the reaction evolution the substrates even at higher concentrations are gradually consumed (Fig. 6B), and the reactions reach a similar yield of $\beta$-sitosteryl myristate ( $>90 \%$ ) at $24 \mathrm{~h}$ (data not shown).

\subsection{Effects of reaction temperatures on synthesis of $\beta$-sitosteryl myristate}

The solubility of substrates in solvent, thermostability and activity of the lipase are strongly associated with reactions temperature [40]. As depicted in Fig. 7, regardless of incubation time CAL A shows a better catalytic activity over the range of $40-50{ }^{\circ} \mathrm{C}(P<0.05)$ among the test range of temperature $\left(30-60^{\circ} \mathrm{C}\right)$, which is of a typical profile of thermostability of an enzyme. Lower conversion of $\beta$-sitosterol at $30^{\circ} \mathrm{C}$ is probably due to lower solubility of substrates and lower enzyme kinetics; while at $60^{\circ} \mathrm{C}$ a slight decrease in the yield of $\beta$-sitosterol most likely is because increasing deactivation at enhanced temperature. Depending on reaction, solvent environment, microbial sources and immobilization process [40,41], the optimal temperature of CAL A can be varied from 50 to $70^{\circ} \mathrm{C}$. In this application, at $50^{\circ} \mathrm{C}$ CAL A exhibits preferable yield and thus determined as an optimal temperature.

\subsection{Effects of solvent properties on synthesis of $\beta$-sitosteryl myristate}

In non-aqueous phase biocatalysis system, the enzyme activity can be largely influenced by the property of solvents (often correlated with its hydrophobicity) [35,42]. Thus, the effect of organic solvents with a broad spectrum of $\log P$ values on the production of $\beta$-sitosteryl ester catalyzed by CAL A was investigated and the results were depicted in Fig. 8. In the increasing order of $\log P$ values [35], the solvents tested are acetonitrile $(-0.33)$, acetone $(-0.23)$, butanone (0.29), tert-butyl methyl ether (TBME) (1.06), chloroform (2.0), toluene (2.5), $n$-hexane (3.5) and $n$-heptane (4.0). In general, solvent may influence enzyme activity in two ways [40,42]: (1) determine the solubility of substrates thus affects availability of substrates for biocatalysis; (2) distort water activity available for maintaining enzyme activity. As a substrate $\beta$-sitosterol has better solubility in lower $\log P$ solvents like acetonitrile, acetone, butanone, etc. [39], therefore, the lower yield of $\beta$-sitosteryl ester cannot be ascribed to their solubilities but their unfavorable properties to enzyme activity. In fact, the yield of $\beta$-sitosteryl myristate has a pronounced correlation with the $\log P$ value of a solvent (Fig. 8), where the solvation interaction of solvent with water plays dominating role. Agreeing with the solvent-enzyme activity rule [35], $\log P$ values of acetonitrile, acetone and butanone are $<1.0$, the yield of product is $<3 \% ; 1.0<\log P$ values of TBME and chloroform are $\leq 2.0$, improved yield obtained; $\log P$ value of toluene is $>2.0$, the yield adds up to about $84 \%$; and maximal yields achieved (92-96\%) with the solvents (hexane and heptane) having $\log P$ values close to 4.0. Similar observations were also reported in other reaction systems $[23,27]$. Actually, less toxic hexane as a process solvent is still allowed for food manufacture, which may represent another benefit.

Interestingly, the esterification in a solvent-free system also yields considerable product (Fig. 8), which an obvious drawback is a slow reaction rate, for example, it takes $72 \mathrm{~h}$ to reach $56 \%$ yield. A further investigation may be of interest; however, it is beyond the focus of this work.

\section{Conclusion}

In conclusion, a series of $\beta$-sitosteryl esters of saturated fatty acids have been synthesized via $C$. antarctica lipase A (CAL A) catalyzed esterification, and the structures of the products have been identified by FTIR and ${ }^{1} \mathrm{H}$ NMR. CAL A shows superior activity over other lipases in biocatalysis (6-14 fold). Using optimized conditions obtained with myristic acid as a model substrate, namely hexane as a solvent, $40-50{ }^{\circ} \mathrm{C}, 5-10 \%$ enzyme load, mole ratio of substrates $1: 1$, substrate concentration at $0.2-0.3 \mathrm{M}$ and $24 \mathrm{~h}, 93-98 \%$ yield of phytosteryl esters can be expected. The reaction time can be further shortened to $6 \mathrm{~h}$ ( $>93 \%$ yield of $\beta$-sitosteryl myristate) at a cost of high enzyme load. This work demonstrated promising potential of CAL A in bioprocess of phytosterols for value-added application. 


\section{Acknowledgements}

Worawan Panpipat gratefully thanks the Royal Thai Government and Aarhus University for financial support of her Ph.D. study.

\section{References}

[1] P. Fernandes, J.M.S. Cabral, Phytosterols: applications and recovery methods, Bioresour. Technol. 98 (2007) 2335-2350.

[2] F. Marangoni, A. Poli, Review: phytosterols and cardiovascular health, Pharm. Res. 61 (2010) 193-199.

[3] P.J.D. Bouic, Sterols and sterolins: new drugs for the immune system? Drug Discov. Today 7 (2002) 775-778.

[4] C.O. Okoli, P.A. Akah, Mechanisms of the anti-inflammatory activity of the leaf extracts of Culcasia scandens P. Beauv (Araceae), Pharmacol. Biochem. Behav. 79 (2004) 473-481.

[5] B. Nashed, B. Yeganeh, K.T. Hayglass, M.H. Moghadasian, Antiatherogenic effects of dietary plant sterols are associated with inhibition of proinflammatory cytokine production in Apo E-KO mince, J. Nutr. 135 (2005) 2438-2444.

[6] Y.H. Choi, K.R. Kong, Y.A. Kim, K.O. Jung, J.H. Kil, S.H. Rhee, K.Y. Park, Induction of Bax and activation of caspases during beta-sitosterol-meadiated apoptosis in human colon cancer cells, Int. J. Oncol. 23 (2003) 1657-1662.

[7] A. Beger, P.J.H. Jones, S.S. Abumweis, Plant sterols: factors affecting their efficacy and safety as functional food ingredients, Lipid Health Dis. 3 (2004) 5-23.

[8] O. Gabay, C. Sanchez, C. Salvat, F. Chevy, M. Breton, G. Nourissat, C. Wolf, C. Jacques, F. Berenbaum, Stigmasterol: a phytosterol with potential antiosteoarthritic properties, Osteoarthritis Cartilage 18 (2010) 106-116.

[9] B.M. Folmer, Sterol surfactant: from synthesis to applications, Adv. Colloid Interface Sci. 103 (2003) 99-119, Review.

[10] N. Weber, P. Weitkamp, K.D. Mukherjee, Cholesterol-lowering food additives: lipase-catalysed preparation of phytosterol and phytostanol esters, Food Res. Int. 35 (2002) 177-181.

[11] P. Nestel, M. Cehun, S. Pomeroy, Cholesterol-lowering effects of plant sterol esters and non-esterified stanols in margarine, butter and low-fat foods, Eur. J. Clin. Nutr. 55 (2001) 1084-1090.

[12] R.P. Mensink, S. Ebbing, M. Lindhout, J. Plat, M.M.A. van Heugten, Effects of plant stanol esters supplied in low-fat yoghurt on serum lipids and lipoproteins, noncholesterol sterols and fat soluble antioxidant concentrations, Atherosclerosis 160 (2002) 205-213.

[13] S.S. Abumweis, C.A. Vanstone, N. Ebine, A. Kassis, L.M. Ausman, P.J. Jones, Intake of a single morning dose of standard and novel plant sterol preparations for 4 weeks does not dramatically affect plasma lipid concentrations in humans, J. Nutr. 136 (2006) 1012-1016.

[14] M. Noakes, P.M. Clifton, A.M. Doornbos, E.A. Trautwein, Plant sterol esterenriched milk and yoghurt effectively reduce serum cholesterol in moderately hypercholesterolemic subjects, Eur. J. Clin. Nutr. 44 (2005) 214-222.

[15] R. Volpe, L. Niittynen, R. Korpela, C. Sirtori, A. Bucci, N. Fraone, Effects of yoghurt enriched with plant sterols on serum lipids in patients with moderate hypercholesterolaemia, Br. J. Nutr. 86 (2001) 233-239.

[16] M. Shin, S. Rim, Y. Jang, D. Choi, S. Kang, S. Cho, S. Kim, D.K. Kim, K. Song, N. Chung, The cholesterol-lowering effect of plant sterol-containing beverage in hypercholesterolemic subjects with low cholesterol intake, Nutr. Res. 23 (2003) 489-496.

[17] R.E. Ostlund Jr., Phytosterols cholesterol absorption and healthy diets, Lipids 42 (2007) 41-45.

[18] T. Heinemann, G. Axtmann, K. von Bergmann, Comparison of intestinal absorption of cholesterol with different plant sterols in man, Eur. J. Clin. Invest. 23 (1993) 823-831.

[19] D. Lütjohann, I. Björkhem, U.F. Beil, K. von Bergmann, Sterol absorption and sterol balance in phytosterolemia evaluated by deuterium-labeled sterols: effect of sitostanol treatment, J. Lipid Res. 36 (1995) 1763-1773.
[20] F. Czubayko, B. Beumers, S. Lammsfuss, D. Lütjohann, K. von Bergmann A simplified micro-method for quantification of fecal excretion of neutral and acidic sterols for outpatient studies in humans, J. Lipid Res. 32 (1991) 1861-1867.

[21] M. Hossen, E. Hernandez, Phospholipase D-catalyzed synthesis of novel phospholipid-phytosterol conjugates, Lipids 39 (2004) 777-782.

[22] T.A. Miettinen, H. Vanhanen, Dietary sitostanol related to absorption, synthesis and serum level of cholesterol in different apolipoprotein E phenotypes, Atherosclerosis 105 (1994) 217-226.

[23] W. He, C. Jia, Y. Ma, Y. Yang, X. Zhang, B. Feng, L. Yue, Lipase-catalyzed synthesis of phytostanyl esters in non-aqueous media, J. Mol. Catal. B: Enzyme 67 (2010) 60-65.

[24] N. Weber, P. Weitkamp, K.D. Mukherjee, Fatty acid steryl stanyl, and steroid esters by esterification and transesterification in vacuo using Candida rugosa lipase as catalyst, J. Agric. Food Chem. 49 (2001) 67-71.

[25] P. Villeneuve, F. Turon, Y. Caro, R. Escoffier, B. Baréa, B. Barouh, R. Lago, G. Piombo, M. Pina, Lipase-catalyzed synthesis of canola phytosterols oleate esters as cholesterol lowering agents, Enzyme Microb. Technol. 37 (2005) 150-155.

[26] G. Torrelo, C.F. Torres, F.J. Señorans, R.M. Blanco, G. Reglero, Solvent-free preparation of phystosteryl esters with fatty acids from butterfat in equimolecular conditions in the presence of a lipase from Candida rugosa, J. Chem. Technol. Biotechnol. 84 (2009) 745-750.

[27] P.-L. Vu, J.-A. Shin, C.-H. Lim, K.-T. Lee, Lipase-catalyzed production of phytosteryl esters and their crystallization behavior in corn oil, Food Res. Int. 37 (2004) 175-180.

[28] S. Negishi, I. Hidaka, I. Takahashi, S. Kunita, Transesterificaiton of phytostero and edible oil by lipase powder at high temperature, J. Am. Oil Chem. Soc. 80 (2003) 905-907.

[29] O. Kirk, M.W. Christensen, Lipase from Candida antarctica: unique biocatalysts from a unique origin, Org. Process Res. Dev. 6 (2002) 446-451.

[30] W. Panpipat, X. Xu, Z. Guo, Towards a commercially potential process: enzymatic recovery of phytosterols from plant oil deodoriser distillates mixture, Process Biochem. 42 (2012) 1256-1262.

[31] C.F. Torres, T. Fornari, G. Torrelo, F.J. Senorans, G. Reglero, Production of phytosterol esters from soybean oil deodorizer distillates, Eur. J. Lipid Sci. Technol. 111 (2009) 459-463.

[32] R.G.D. Steel, J.H. Torrie, Principle and Procedure of Statistics, 2nd ed., MacGrawHill, New York, 1980.

[33] E.P. Serjeant, B. Dempsey, Ionization Constants of Organic Acids in Aqueous Solution, Pergamon, Oxford, 1979.

[34] E. Matthew, A. McKenzie, B. Barbara, A. Martin, F.M. Dean, Comparison of $\log P$ values obtained from CAChe and other sources, J. Environ. Sci. Health A 38 (2003) 511-519.

[35] C. Laane, S. Boeren, K. Vos, C. Veeger, Rules for optimization of biocatalysis in organic media, Biotechnol. Bioeng. 30 (1987) 81-87.

[36] The Merck Index: An Encyclopedia of Chemicals, Drugs, and Biologicals, 11th ed., Merck, Rahway, NJ. USA, 1989.

[37] A. Kamboj, A. Saluja, Isolation of stigmasterol and $\beta$-sitosterol from petroleum ether extract of aerial parts of Ageratum conyzoides (Asteraceae), Int. J. Pharm. Pharm. Sci. 3 (2011) 94-96.

[38] Y. Shimada, Y. Hirota, T. Baba, A. Sugihara, S. Moriyama, Y. Tominaga, T. Terai Enzymatic synthesis of steryl esters of polyunsaturated fatty acids, J. Am. Oil Chem. Soc. 76 (1999) 713-716.

[39] D. Wei, L. Wang, C. Liu, B. Wang, Sitosterol solubility in selected organic solvents, J. Chem. Eng. Data 55 (2010) 2917-2919.

[40] C. Yang, F. Wang, D. Lan, C. Whiteley, B. Yang, Y. Wang, Effects of organic solvents on activity and conformation of recombinant Candida antarctica lipase A produced by Pichia pastoris, Process Biochem. 47 (2012) 533-537.

[41] A. Dimitrijevic, D. Velickovic, F. Bihelovic, D. Bezbradica, R. Jankov, N. Milosavic One-step, inexpensive high yield strategy for Candida antarctica lipase A isolation using hydroxyapatite, Bioresour. Technol. 107 (2012) 358-362.

[42] A.M. Klibanov, Improving enzymes by using them in organic solvents, Nature 409 (2001) 241-246. 